Rory Hillocks (r.j.hillocks@gre.ac.uk) is an agriculturalist at the Natural Resources Institute, Chatham, UK, with 30 years of experience in crop management for African smallholders; Midatharahally Maruthi (m.n.maruthi@gre.ac.uk) is a plant virologist at the Natural Resources Institute, Chatham, UK, acknowledged for his research on virus transmission on and host-plant resistance to CBSD

\title{
Post-harvest impact of cassava brown streak disease in four
}

\section{countries in eastern Africa}

\author{
RODERICK J. HILLOCKS and MIDATHARAHALLY N. MARUTHI
}

Cassava brown streak disease (CBSD) is endemic to the coast of East Africa and the disease continues to spread to new areas in the Great Lakes region. In both these areas CBSD leaf symptoms occur at high incidences. However, it is the associated symptom of necrosis in the starch-bearing tissues that renders the root unfit for human consumption. Where root necrosis occurs, the economic viability of processing into flour is adversely affected. Surveys undertaken in Tanzania, Kenya, Uganda, and Malawi showed that CBSD leaf symptoms were present at high incidences but root necrosis incidence was lower than would be expected. It appears that a form of tolerance to CBSD occurs in which the plants are susceptible to infection by the virus but are less affected by the root symptom. Farmers practise selection for cassava varieties less prone to CBSD root necrosis leading to dependence on a decreasing number of varieties.

Keywords: cassava, CBSD, root necrosis, yield loss

WITHIN THE CURRENT MILLENNIUM cassava brown streak disease (CBSD) has spread from the East African coast where it has been endemic for more than 70 years (Hillocks and Jennings, 2003), to affect most of the countries of the Great Lakes region. During and prior to the 1990s, CBSD had been found at high incidences in cassava fields from the Kenyan littoral down to the Zambezi River in Mozambique, including the Lake shore region of Malawi. At the time, the disease was confined to coastal zones and cassava fields below $1000 \mathrm{~m}$ above sea level. However, by around 2004, leaf symptoms resembling those of CBSD were being increasingly seen in Uganda (Alicai et al., 2007) and, as the symptoms began to spread across Uganda and into the neighbouring countries of Kenya, Tanzania, and later into Burundi, Rwanda, and the Democratic Republic of Congo, the cassava brown streak viruses (CBSVs) were confirmed as the cause (Patil et al., 2014). The viruses can be introduced into previously unaffected fields through the planting of infected cassava cuttings (the normal method of 
propagation) and within fields and between neighbouring fields by an insect vector, the whitefly (Bemisia tabaci) (Maruthi et al., 2005).

\section{Importance of CBSD}

The 'syndrome' of CBSD includes symptoms on the leaves, stem, and roots but it is the symptom of root necrosis which is most damaging and can cause total crop loss in individual plants. Infection by the virus may cause a decrease in root weight, the extent of which depends on cassava variety. The main source of crop loss is, however, the symptom of root necrosis that renders the root partly or completely unsuitable for human consumption (Hillocks and Jennings, 2003) (Figure 1). As cassava becomes increasingly used in Africa as a source of value added products and as a source of income for smallholders, CBSD poses a potential constraint to root supply for domestic and commercial processing.

Figure 1 Scoring system used to assess severity of root necrosis

\section{Cassava processing}

In much of sub-Saharan Africa between the two tropics, cassava is second to maize in importance as a starch staple and in some parts it is the primary source of carbohydrate. Even where maize is the dominant staple, cassava is grown in addition and serves a crucial role as an insurance against failure of the cereal crop. The sweet varieties of cassava can be eaten fresh but surplus production and the bitter varieties are processed into flour for cooking in the home or for sale. The traditional method of processing is to peel the roots, cut them into smaller pieces, sometimes ferment them and/or dry them for preservation. There is a thriving local market for this dried product which is milled into flour with a fermented flavour.

Cassava can also be processed into high quality cassava flour (HQCF) that can substitute for wheat or maize flour in a number of bakery and industrial products. Partial or complete substitution of cassava flour for wheat flour in bakery products takes advantage of a locally grown crop and could significantly decrease the reliance on imported wheat in a number of African countries.

\section{[A]Effect of CBSD on root quality}

Costs of production and aggregation are high for cassava in Africa due to low yields, its high volume to weight ratio, and poor rural road and transport networks. The profitability of community-based and larger commercial HQCF processing depends on efficient conversion of fresh root to flour. CBSD root necrosis has several effects on processing efficiency. First, roots may become scarce in areas where CBSD is prevalent, resulting in higher prices. Second, if diseased roots or portions of the root have to be discarded, the conversion ratio decreases below the optimum of 3.5 or $4: 1$. Third, the labour required to peel and chip the roots before grating is increased if diseased portions have to be excised. As cassava 
processing is increasingly seen as an income-generating option for households and small enterprises, it is important to understand the impact of CBSD on cassava production, consumption, and processing.

\section{[A]Impact of CBSD on production and processing}

Recent research conducted in villages in Kenya, Tanzania, Uganda, and Malawi confirmed the widespread occurrence of CBSD leaf symptoms at high incidences (above 50 per cent). Surprisingly, this was not associated with a similarly high incidence of root necrosis. Severe root necrosis was found only in a few varieties usually representing a small proportion of the cassava crop. Nevertheless, moderately severe necrosis (grade 3 or above on a 1-5 scale) was found in 6-13 per cent of the cassava roots examined (Figure 2). Such production losses may not be significant in areas where root yields are high, but might decrease food security in areas such as the Lake Zone of Tanzania where in Sengerema District yields are only $8 \mathrm{~kg} \mathrm{ha}$ 1 . CBSD root necrosis causes losses for household consumption when the necrotic portions have to be cut out before food can be prepared. Furthermore, roots affected by CBSD cannot be sold to processors. HQCF cannot be made from roots showing CBSD necrosis severity score of 3 or above due to decreased $\mathrm{pH}$ and starch content and a dark colour. Exact losses are difficult to estimate as they differ for household consumption and for processing. When cassava is scarce households may remove necrotic areas and sometimes use roots with a severity score of three. For a single household the proportion of their cassava affected by CBSD necrosis depends on the varieties they grow. For commercial processing, roots with a score of three or above are not acceptable and so the value shown in Figure 2 for percentage of roots with necrosis score above three is also the loss estimate. With around 36 million tonnes of cassava produced annually in the survey area, 8 per cent loss would be just under 3 million tonnes, valued at US\$750 m, based on $\$ 250$ per metric tonne.

[CAP]Figure 2 Incidence of CBSD leaf symptoms and percentage of harvested roots showing CBSD necrosis symptom severity of grade 3 or above (1-5 scale where grade $1=$ no disease) $(\mathrm{TZ}=$ Tanzania $)$

\section{[A]Impact of CBSD on processing enterprises}

Households view CBSD as a problem and estimate losses to the disease at 10-25 per cent. Both households and processors may have to use roots affected by CBSD when cassava is scarce and then must cut out the affected portions. Research has shown that the amount of tissue lost by cutting out diseased portions ranges from 10-60 per cent for roots showing CBSD severity grades 2-5 (Figure 3) (Abayomi et al., in press). However, a type of tolerance to CBSD occurs in the general cassava gene pool in which a variety may be fully susceptible to infection by the viruses and show typical leaf symptoms but has a low propensity to develop root necrosis. Communities in areas with a high incidence of CBSD replace the root necrosis susceptible types with the tolerant ones. As a consequence processors are still able to obtain sufficient roots free of CBSD necrosis and the impact of CBSD on the profitability of processing enterprises is less than would otherwise be the case. The main impact of CBSD in 
these areas has been to decrease the number of cassava varieties being grown. This loss of germplasm is particularly marked in eastern Uganda and the Lake shore region of Malawi, where there is almost total reliance on a single variety (Table 1). This poses a food security risk and a risk to processing enterprises, should those varieties later succumb to CBSD or another pest or disease epidemic.

[CAP]Figure 3 Percentage loss of starch-bearing tissue when portions affected by CBSD root necrosis grades $1-5$ are removed before processing

[S]Source: Data from a community processing enterprise in Tanzania

The adverse impact of CBSD is much greater when the disease first arrives in an area before farmers identify varieties that display tolerance to CBSD, manifested as a decreased propensity to develop root necrosis.

\section{[A]Long-term solution to CBSD?}

As CBSD continues to spread in eastern and central Africa the disease must be managed to decrease its impact on household food security and income from processing. It seems that farmers themselves have recognized that some varieties show tolerance to CBSD and that they are less prone to root necrosis. However, these varieties are fully susceptible to infection by the viruses and their widespread propagation maintains virus inoculum at high levels. The long-term solution is to develop varieties with true resistance to CBSD in which virus replication is retarded and which show a low incidence of both leaf and root symptoms. This type of resistance is seen in the varieties Namikonga and Migyera and it will be important to fully exploit this resistance by identifying more sources of resistance and to understand the underlying mechanisms and genetics.

\section{[A]Conclusions}

CBSD is widely distributed in eastern and central Africa and occurs at high incidences in cassava fields in the principal cassava-growing areas of at least seven countries.

The leaf symptoms are the most visible manifestation of CBSD but the most damaging symptom is root necrosis which can render the roots unfit for processing and in severe cases unfit for human consumption.

When CBSD root necrosis occurs, the profitability of cassava processing enterprises is adversely affected by the additional time taken to cut out affected portions of the root and by a decreased root to flour conversion ratio due to the resulting tissue loss.

Roots with a CBSD necrosis severity grade of 3 or above are unsuitable for processing into HQCF due to the dark colour, decrease in $\mathrm{pH}$, and starch content. 
Losses to CBSD are greatest in areas more recently affected by the disease but as the epidemic establishes, households begin to discard those varieties that are most susceptible to root necrosis in favour of those that are less prone to necrosis.

Because of the widespread availability of cassava varieties that are less prone to root necrosis, although fully susceptible to infection and which show typical leaf symptoms, the adverse impact of CBSD on processing enterprises is less than might otherwise be the case.

Many useful cassava varieties are being discarded due to their susceptibility to CBSD root necrosis, particularly in astern Uganda and the Lakeshore region of Malawi, where communities for which cassava is the primary food staple are at risk of food insecurity due to dependence on only one or two varieties.

\section{[A]References}

Abayomi, L.A., Hillocks, R.J., Maruthi, M.N. and Westby, A. (in press) 'Impact of cassava brown streak disease on cassava processing and the value chain in Eastern Africa', Post Harvest Biology and Technology (submitted February 2015).

Alicai, T., Omongo, C.A., Maruthi, M.N., Hillocks, R.J., Baguma, Y., Kawuki, R., Bua, A., Otim-Nape, G.W., and Colvin, J. (2007) 'Re-emergence of cassava brown streak disease in Uganda’, Plant Disease 91: 24-9 <http://dx.doi.org/10.1094/PD-91-0024>.

Hillocks, R.J. and Jennings, D.L. (2003) 'Cassava brown streak disease: a review of present knowledge and research needs', International Journal of Pest Management 49: 225-34 $<$ http://dx.doi.org/10.1080/0967087031000101061>.

Maruthi, M.N., Hillocks, R.J., Mtunda, K., Raya, M.D., Muhanna, M., Kiozia, H., Rekha. A.R. and Colvin, J. (2005) 'Transmission of Cassava brown streak virus by Bemisia tabaci (Gennadius)’, Journal of Phytopathology 153: 307-12 <http://dx.doi.org/10.1111/j.14390434.2005.00974.x>.

Patil, B.L., Legg, J.P., Kanju, E. and Fauquet, C.M. (2014) 'Cassava brown streak disease: a threat to food security in Africa', Journal of General Virology [online]

$<$ http://dx.doi.org/10.1099/vir.0.000014-0>. 
[CAP]Table 1 Number of different cassava varieties found during disease surveys conducted in selected villages in four countries in sub-Saharan Africa

\begin{tabular}{lll}
\hline Location & No of varieties & $\begin{array}{l}\text { \% of crop derived from } 3 \text { most } \\
\text { common varieties }\end{array}$ \\
\hline Kenya (Migori County) & 14 & 57 (42\% Weite) \\
Tanzania (Lake Zone) & 5 & 82 (52\% Mwanaminzi) \\
Village 1 & 4 & 94 (60\% Ngarabuto) \\
Village 2 & 6 & 78 (47\% Lufaili) \\
Village 3 & & \\
Tanzania (Southern Zone) & 6 & 69 (29\% Musa Saidi) \\
Village 1 & 7 & 77 (34\% Kigoma Red) \\
Village 2 & 6 & 81 (38\% Kigoma Red) \\
Village 3 & & \\
Malawi (Lake shore) & 3 & 92 (41\% Twenty:Twenty) \\
Village 1 & 3 & 91 (65\% Twenty:Twenty) \\
Village 2 & 3 & 84 (78\% Twenty:Twenty) \\
Village 3 & & \\
Uganda (Eastern) & 3 & 91 (83\% Migyera) \\
Village 1 & 2 & 99 (57\% Migyera) \\
Village 2 & 2 & 100 (93\% Migyera) \\
Village 3 & &
\end{tabular}




\section{Post-harvest impact of cassava brown streak disease in four}

\section{countries in eastern Africa}

HILLOCKS, R.J., MARUTHI, M.N. Natural Resources Institute, University of Greenwich, Chatham Maritime, Kent ME4 4TB, UK

Short title: CBSD post-harvest impact

Key words: Cassava, CBSD, root necrosis, yield loss

Cassava brown streak disease is endemic to the coastal regions of East Africa and from around 2004 the disease resurged and became epidemic in the Great Lakes Region, where it continues to spread. In both these areas CBSD leaf symptoms occur at high incidences. However, it is the associated symptom of root rot (necrosis) in the starch-bearing tissues that renders the root unfit for human consumption. Where severe root necrosis occurs research has shown that the economic viability of processing into flour is affected in several ways. There may be a scarcity of healthy roots which inflates the price of raw material for processing. If diseased roots are to be used for processing then first, the necrotic portions must be removed which adds time to processing and the loss of starch-bearing tissue can exceed 25\%, making processing into flour uneconomic. If the diseased portions of the root are not removed then the quality of the resulting flour is adversely affected. Because the extent of root necrosis it not known until the crop is harvested and surveys require destructive sampling, root symptoms are much less frequently assessed than are the aboveground symptoms on the leaves and stems. Surveys were undertaken in Tanzania, Kenya, Uganda and Malawi to assess the incidence of CBSD leaf symptoms and the incidence and severity of root symptoms, in order to estimate the impact of the disease on household food security and on cassava processing. CBSD leaf symptoms were recorded at high incidences [40 - 90\% in individual fields] in all fields visited throughout East Africa but root necrosis incidence was lower than would be expected from the high incidence of leaf symptoms.

Severe root necrosis at high incidence was found only on a few varieties, usually grown to a limited extent. It appears that a form of tolerance to CBSD occurs quite widely in cassava in which the plants are fully susceptible to infection by the virus but are less affected by the root necrosis symptom. In communities where cassava is the primary starch staple, active selection is practised for varieties less prone to CBSD root necrosis and this has led to the loss of varietal diversity and dependence on a decreasing number of varieties. 


\section{Cassava brown streak disease affects cassava in most of the countries of eastern and central Africa.}

Within the current millennium CBSD has spread from the East African coast where it has been endemic for more than 70 years (Hillocks and Jennings, 2003), to affect most of the countries of the Great Lakes region. During and prior to the 1990s, CBSD had been found at high incidences in cassava fields from the Kenyan littoral down to the Zambezi River in Mozambique, including the Lakeshore region of Malawi. At the time, the disease was confined to coastal zones and cassava fields below $1000 \mathrm{~m}$ above sea level. However, around 2004 leaf symptoms resembling those of CBSD were being increasingly seen in Uganda (Alicai et al., 2007) and as the symptoms began to spread across Uganda and into the neighbouring countries of Kenya, Tanzania and later into Burundi, Rwanda and the Democratic Republic of Congo, the cassava brown streak viruses were confirmed as the cause (Patil et al., 2015). The viruses can be introduced into previously unaffected fields through the planting of infected cassava cuttings [the normal method of propagation] and within fields and between neighbouring fields by an insect vector, the whitefly (Bemisia tabaci) (Maruthi et al., 2005).

\section{CBSD is especially damaging due to the direct effect on cassava roots}

The 'syndrome' of CBSD includes symptoms on the leaves, stem and roots but it is the symptom of root necrosis which is most damaging and can cause total crop loss in individual plants. Infection by the virus may cause a decrease in root weight, the extent of which depends on cassava variety. The main source of crop loss is however, the symptom of root necrosis that renders the root partly or completely unsuitable for human consumption (Hillocks and Jennings,2003) (Fig 1). As cassava becomes increasingly used in Africa as a source of value added products and as a source of income for smallholders, CBSD poses a potential constraint to root supply for domestic and commercial processing.

\section{Cassava is an important staple food and can be processed into flour and other products}

In much of Sub-Saharan Africa between the two tropics, cassava is second to maize in importance as a starch staple and in some parts it is the primary source of carbohydrate. Even where maize is the dominant staple, cassava is grown in addition and serves a crucial role as an insurance against failure of the cereal crop. The sweet varieties of cassava can be eaten fresh but surplus production and the bitter varieties are processed into flour for cooking in the home or for sale. The traditional method of processing is to peel the roots, cut them into smaller pieces, sometimes ferment them and /or dry them for preservation. There is a thriving local market for this dried product which is milled into flour with a fermented flavour.

Cassava can also be processed into high quality cassava flour (HQCF) that can substitute for wheat or maize flour in a number of bakery and industrial products. Partial or complete substitution of cassava flour for wheat flour in bakery products takes advantage of a locally grown crop and could significantly decrease the reliance on imported wheat in a number of African countries. 


\section{Roots showing symptoms of CBSD are unsuitable for processing into HQCF}

Costs of production and aggregation are high for cassava in Africa due to low yields, its high volume to weight ratio and poor rural road and transport networks. The profitability of community-based and larger commercial HQCF processing depends on efficient conversion of fresh root to flour. CBSD root necrosis has several effects of processing efficiency. First roots may become scarce in areas where CBSD is prevalent, resulting in higher prices.

Secondly, if diseased roots or portions of the root have to be discarded, the conversion ratio decreases below the optimum of 3.5 or $4: 1$. Thirdly, the labour required to peel and chip the roots before grating is increased if diseased portions have to be excised. As cassava processing is increasingly seen as an income-generating option for households and small enterprises, it is important to understand the impact of CBSD on cassava production, consumption and processing.

\section{CBSD impacts on both production and processing}

Recent research conducted in villages in Kenya, Tanzania, Uganda and Malawi confirmed the widespread occurrence of CBSD leaf symptoms at high incidences [above 50\%].

Surprisingly, this was not associated with a similarly high incidence of root necrosis. Severe root necrosis was found only in a few varieties usually representing a small proportion of the cassava crop. Nevertheless, moderately severe necrosis [grade 3 or above on a 1-5 scale] was found in $6-13 \%$ of the cassava roots examined (Fig.2). Such production losses may not be significant is areas where root yields are high but might decrease food security in areas such as the Lake Zone of Tanzania where in Sengerema District yields are only $8 \mathrm{~kg} \mathrm{ha}^{-1}$. CBSD root necrosis causes losses for household consumption when the necrotic portions have to be cut out before food can be prepared. Furthermore, roots affected by CBSD cannot be sold to processors. High quality cassava flour [HQCF] cannot be made from roots showing CBSD necrosis severity score of 3 or above due to decreased $\mathrm{pH}$ and starch content and having a dark colour.

\section{What is the overall impact of CBSD on processing enterprises?}

Households view CBSD as a problem and estimate losses to the disease at $10-25 \%$. Both households and processors may have to use roots affected by CBSD when cassava is scarce and then must cut-out the affected portions. Research has shown that the loss of tissue due to cutting out diseased portions ranges from $10-60 \%$ for roots showing CBSD severity grades 2 - 5 (Fig 3) (Abayomi et al., in press). However, a type of tolerance to CBSD occurs in the general cassava gene pool in which a variety may be fully susceptible to infection by the viruses and show typical leaf symptoms but have a low propensity to develop root necrosis. Communities in areas with a high incidence of CBSD replace the root necrosis susceptible types with the tolerant ones. As a consequence processors are still able to obtain sufficient roots free of CBSD necrosis and the impact of CBSD on the profitability of processing enterprises is less than would otherwise be the case. The main impact of CBSD in these areas has been to decrease the number of cassava varieties being grown. This loss of germplasm is particularly marked in Eastern Uganda and the Lakeshore region of Malawi, where there is 
almost total reliance on a single variety (Table 1). This poses a food security risk and a risk to processing enterprises, should those varieties later succumb to CBSD or another pest or disease epidemic.

The adverse impact of CBSD is much greater when the disease first arrives in an area before farmers identify varieties that display tolerance to CBSD, manifested as a decreased propensity to develop root necrosis.

\section{Resistant varieties offer a long-term solution to CBSD?}

As CBSD continues to spread in Eastern and Central Africa the disease must be managed to decrease its impact on household food security and income from processing. It seems that farmers themselves have recognised that some varieties show tolerance to CBSD and that they are less prone to root necrosis. However, these varieties are fully susceptible to infection by the viruses and their widespread propagation maintains virus inoculum at high levels. The long-term solution is to develop varieties with true resistance to CBSD in which virus replication is retarded and which show a low incidence of both leaf and root symptoms. This type of resistance is seen in the varieties Namikonga and Migyera and it will be important to fully exploit this resistance by identifying more sources of resistance and to understand the underlying mechanisms and genetics.

\section{Conclusions}

CBSD is widely distributed in eastern and central Africa and occurs at high incidences in cassava fields in the principal cassava-growing areas of at least seven countries.

The leaf symptoms are the most visible manifestation of CBSD but the most damaging symptom is root necrosis which can render the roots unfit for processing and in severe cases unfit for human consumption.

When CBSD root necrosis occurs, the profitability of cassava processing enterprises is adversely affected by the additional time taken to cut out affected portions of the root and by a decreased root to flour conversion ratio due to the resulting tissue loss.

Roots with a CBSD necrosis severity grade of 3 or above [1-5 scale] are unsuitable for processing into HQCF due to the dark colour, decrease in $\mathrm{pH}$ and starch content.

Losses to CBSD are greatest in areas more recently affected by the disease but as the epidemic establishes, households begin to discard those varieties that are most susceptible to root necrosis in favour of those that are less prone to necrosis.

Because of the widespread availability of cassava varieties that are less prone to root necrosis, although fully susceptible to infection and which show typical leaf symptoms, the adverse impact of CBSD on processing enterprises is less than might otherwise be the case.

Many useful cassava varieties are being discarded due to their susceptibility to CBSD root necrosis and particularly in Eastern Uganda and the Lake shore region of Malawi, 
communities for which cassava is the primary food staple are at risk of food insecurity due to dependence on only one or two varieties.

\section{References}

Abayomi LA, Hillocks RJ, Maruthi MN, Westby A. Impact of cassava brown streak disease on cassava processing and the value chain in Eastern Africa. Post Harv Biol Technol (submitted February 2015)

Alicai T, Omongo CA, Maruthi MN, Hillocks RJ, Baguma Y, Kawuki R, Bua A, Otim-Nape GW, Colvin J. Re-emergence of cassava brown streak disease in Uganda. Plant Dis. 2007; 91: 24-29.

Patil BL, Legg JP, Kanju E, Fauquet CM. Cassava brown streak disease: a threat to food security in Africa. J Gen Virol 2015; 96 (in press).

Hillocks RJ, Jennings DL. Cassava brown streak disease: A review of present knowledge and research needs. Int J Pest Manage. 2003; 49: 225-234.

Maruthi MN, Hillocks RJ, Mtunda K, Raya MD, Muhanna M, Kiozia H, Rekha AR, Colvin J. Transmission of Cassava brown streak virus by Bemisia tabaci (Gennadius). J Phytopathol. 2005; 153, 307-312. 


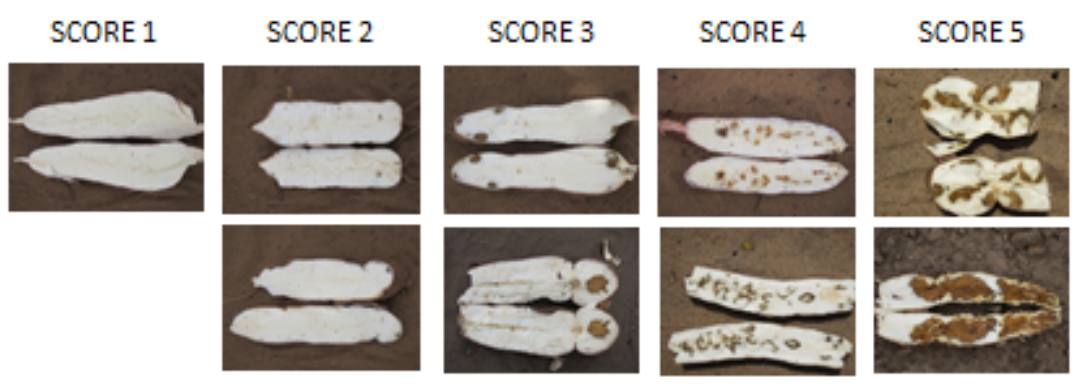

Score 1 = no necrosissymptoms

Score 2 = Trace of necrosis

Score 3 = Clearly defined areas of necrosis but most of root clean and possible to remove necrotic areas

Score 4 = Most of the root contains necrosis, may still be possible to cutout affected areasfor home consumption

Score $5=$ Most or all of root necrotic and unsuitable for human consumption

Fig.1. Longitudinal section of cassava roots showing CBSD necrosis severity grades 1 -5

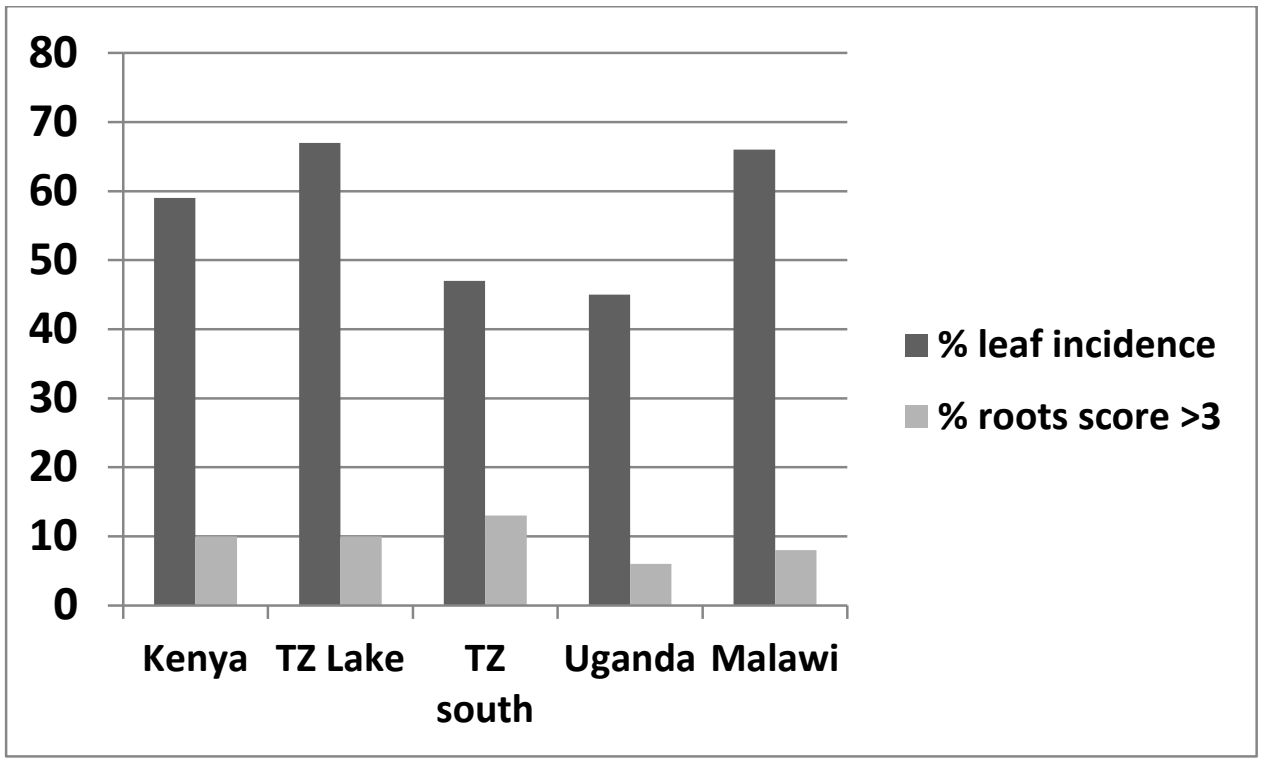

Fig.2. Incidence of CBSD leaf symptoms and percentage of harvested roots showing CBSD necrosis symptom severity of grade 3 or above [1-5 scale where grade $1-$ no disease] (TZ = Tanzania). 


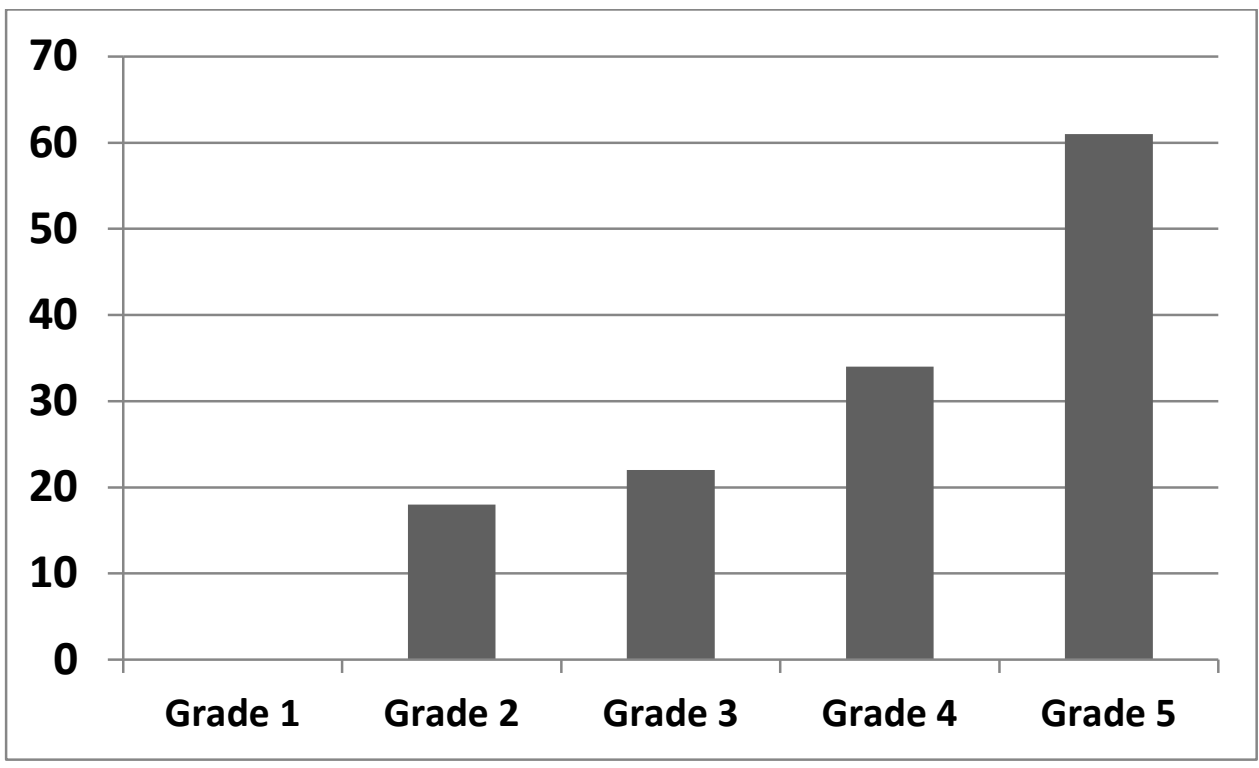

Fig 3. Percentage loss of starch-bearing tissue when areas affected by CBSD root necrosis grades 1 -5 are removed before processing (data from a community processing enterprise in Tanzania) 
Table 1. Number of different cassava varieties found during disease surveys conducted in selected villages in four countries in sub-Saharan Africa

$\begin{array}{ll}\text { Location } & \text { No of varieties }\end{array} \quad \begin{aligned} & \% \text { of crop derived from } 3 \\ & \text { most common varieties }\end{aligned}$

Kenya (Migori County) $\quad 14 \quad 57$ (42\% Weite)

\section{Tanzania (Lake Zone)}

Village 1

Village 2

Village 3

\section{Tanzania (Southern Zone)}

Village 1

Village 2

Village 3

\section{Malawi (Lake shore)}

Village 1

Village 2

Village 3

\section{Uganda (Eastern)}

Village 1

Village 2

Village 3

\section{5}

4

6

82 (52\% Mwanaminzi)

94 (60\% Ngarabuto)

78 (47\% Lufaili)

69 (29\% Musa Saidi)

$7 \quad 77$ (34\% Kigoma Red)

6

81 (38\% Kigoma Red)

92 (41\% Twenty:Twenty)
91 (65\% Twenty:Twenty)
34 (78\% Twenty:Twenty)
91 (83\% Migyera)
299 (57\% Migyera)
2100 (93\% Migyera)

